\title{
Burnout among healthcare professionals during COVID-19 pandemic: a cross-sectional study
}

\author{
Mohammad Jalili $^{1} \cdot$ Mahtab Niroomand $^{2} \oplus \cdot$ Fahimeh Hadavand $^{3} \cdot$ Kataun Zeinali $^{4} \cdot$ Akbar Fotouhi $^{5}$
}

Received: 16 July 2020 / Accepted: 17 January 2021 / Published online: 17 April 2021

(c) The Author(s), under exclusive licence to Springer-Verlag GmbH Germany, part of Springer Nature 2021

\begin{abstract}
Purpose To describe the prevalence of burnout among healthcare professionals dealing with COVID-19 patients and the associated factors.

Methods In this cross-sectional survey, healthcare workers at six university-affiliated hospitals, who had been taking care of COVID-19 patients were studied. Age, gender, marital status, having children, hospital, job category, experience, and work load, as well as the level of burnout in each subscale were measured.

Results 326 persons (53.0\%) experienced high levels of burnout. The average score in emotional exhaustion, depersonalization and lack of personal accomplishment was 26.6,10.2, and 27.3, respectively. The level of burnout in the three subscales varied based on the personal as well as work-related factors and gender was the only variable that was associated with high levels of all three domains.

Conclusions Burnout is prevalent among healthcare workers caring for COVID-19 patients. Age, gender, job category, and site of practice contribute to the level of burnout that the staff experience.
\end{abstract}

Keywords Covid-19 $\cdot$ Burnout $\cdot$ Emotional exhaustion $\cdot$ Pandemic

\section{Introduction}

Since December 2019, COVID-19 has rapidly spread worldwide, affecting people in 210 countries and territories with the current tally exceeding 53 million infected people and more than 1,300,000 deaths (Jin et al. 2020; World Health Organization 2019). In addition to the lives it has claimed

Mahtab Niroomand

m.niroomand@sbmu.ac.ir

1 Emergency Medicine Department, Tehran University of Medical Sciences, Tehran, Iran

2 Department of Internal Medicine, School of Medicine, Shahid Beheshti University of Medical Sciences, 7th Floor, Bldg. No.2 SBUMS, Arabi Ave, Daneshjoo Blvd, Velenjak, 19839-63113 Tehran, Iran

3 Infectious Diseases and Tropical Medicine Research Center, Shahid Beheshti University of Medical Sciences, Tehran, Iran

4 Shohadaye Tajrish Hospital, Shahid Beheshti University of Medical Sciences, Tehran, Iran

5 Department of Epidemiology and Biostatistics, Tehran University of Medical Sciences, Tehran, Iran globally, the pandemic has led to high levels of panic and anxiety throughout the world (Chong et al. 2004; Sim and Chua 2004; World Health Organization 2003; SARS 2006). The first case of COVID-19 in Iran was reported on 18 February 2020, and at the time of this study, the national death toll exceeded 10,000, the ninth highest national death toll in the world (World Health Organization 2020a). By now, the cumulative number of cases has reached an alarming number of nearly 750,000 (World Health organization 2020b).Healthcare providers (HCP) are key players in the management of the pandemic COVID-19, and are inevitably in the front line of exposure to the virus (Draper et al. 2008). Therefore, they comprise a notable proportion of the people who have contracted the illness, with $10 \%$ of confirmed cases in some reports (In Memoriam 2020). A recent report from Iran mentioned that around 10,000 healthcare professionals have contracted COVID-19 and at least 43 are known to have died of this disease (Ing et al. 2020). This high rate of infection and mortality has a tremendous impact on the healthcare system.

Burnout, first described by Maslach et al. (1996), is a state of psychological, emotional, and physical stress in response to prolonged exposure to occupational stress. It includes 
feelings of emotional exhaustion (depletion of emotional resources), depersonalization (developing cynical attitudes about patients), and reduced professional accomplishment (a sense of negative evaluation of oneself).

The deadly and uncontrollable nature of COVID-19 together with relatively high rate of infection and mortality among HCPs can provoke the feelings of anxiety and stress in medical staff. Issues such as social stigmatization, shortage of personal protection equipment supplies, and heavy workload on the staff can aggravate this situation. Therefore, this pandemic is expected to have substantial psychological impact on HCPs (Guo et al. 2020).

Burnout can have serious consequences for both patients and the healthcare professionals. It not only results in poor physical and mental health outcomes, lack of motivation, absenteeism, and low morale in the staff, but also leads to deterioration of the quality of care provided by the affected staff with resulting poor outcomes for patients. Several systematic reviews have found that high levels of burnout in health care professionals are associated with less-safe patient care (Dewa et al. 2017; Hall et al. 2016). These consequences impose immense costs on the society (Dewa et al. 2014; Shanafelt et al. 2016).

Health authorities need more information on the magnitude of this problem and its associated factors to better prepare for future infectious disease outbreaks, and also to adapt sound interventions and implement strategies to alleviate the concerns and fears of HCPs and prevent further deepening of this dreadful situation (Draper et al. 2008).

This study was conducted on healthcare workers providing care for COVID-19 patients and aimed to explore the level of burnout among this population and also to examine factors associated with the development of this psychological sequel.

\section{Methods}

This cross-sectional study was conducted during the current COVID-19 pandemic to evaluate the level of burnout among HCPs who were taking care of covid-19 patients at six university-affiliated hospitals. Altogether, these hospitals cover about one-third of Tehran province with a catchment area of about 4,000,000. The study was conducted about 2 months after the onset of the outbreak and when the disease had not yet been controlled.

Study participants included all HCPs (i.e., physicians, residents, interns, and nurses) who had taken care of COVID-19 patients at any time during the first 2 months of the outbreak. Exclusion criteria were those with no patient contact during the outbreak or those unwilling to participate.

The Institutional Review Board granted approval and the requirement for written informed consent was waived based on the recognition that answering the survey instrument implied consent. Participation was voluntary and anonymity was assured. All personal information was kept confidential. Furthermore, researchers analyzed only de-identified data.

The data collection instrument comprised of two parts: The first part of the tool asked questions pertaining sociodemographic and work-related characteristics. The choice of variables was informed by the available literature and inputs from the investigators. Participants were requested to indicate their age, gender, marital status, number of children, job title, place of work, and years of experience. This section also asked whether the respondent had been involved in the care of COVID-19 patients and if yes for how many shifts a month and how many hours per shift. The second part of the study tool was a translated version of Maslach burnout inventory (MBI) for human services survey. To limit the study to burnout related to COVID-19, the phrase "due to COVID-19" was added to each item. MBI is an internationally recognized, validated, self-report questionnaire for measuring the severity of workplace burnout (Maslach and Jackson 1981), using the three dimensions of emotional exhaustion, depersonalization, and personal accomplishment. The questionnaire has 22 items and each item is answered on a five-point Likert scale. This tool has been extensively used in many studies in different parts of the world and the Persian translation has also been validated previously (Moalemi et al. 2018).

The study used a convenience sampling method for recruitment. Invitation to participate in the study was made through professional as well as informal networks. The message included an invitation explaining the purpose of the study, the name and contact details of the principal investigator, and a live link to the host survey platform (E Poll). The online self-administered questionnaire instructed participants to respond to the statements in the tool in relation to the COVID-19 outbreak. Verbal reminders through faceto-face contact and phone calls were performed on a weekly basis by a site coordinator at each hospital.

Burnout is expressed by scores of each of the three MBI subscales, with a high score meaning a high level of burnout. Each subscale score is calculated by adding up all scores of all items in that subscale, with the notion that the items on personal accomplishment domain are reversely scored (Maslach et al. 1996; Maslach and Jackson 1981). Scores range from 0 to 36 for emotional exhaustion, from 0 to 20 for depersonalization, and from 0 to 32 for personal accomplishment subscale. The standard cut-off values were used to define low, moderate, and high levels in each dimension (Maslach et al. 1996; Maslach and Jackson 1981).

We calculated the "average daily workload" by multiplying the number of shifts per month by the number of work hours per shift divided by 30 . We also defined "high burnout" as obtaining a moderate or high score in either 
emotional exhaustion or depersonalization axes, the two factors sometimes referred to as the core of burnout (Walkey and Green 1992).

Upon completion of the study period, the data were downloaded from the online survey tool entered into an excel spreadsheet and anonymized. These data were, then, imported into the statistical software for analysis.

Descriptive analyses were conducted to examine all baseline characteristics of the participants and the outcome variables. Means and standard deviations (SDs) were calculated for continuous variables, while frequencies and percentages were produced for categorical variables. All reported $p$ values are two-tailed, and $p<0.05$ was considered statistically significant. To explore the risk factors associated with the development of burnout, multivariable logistic regression models were used. Odds ratios and corresponding $95 \%$ confidence intervals $(\mathrm{CI})$ were reported.

\section{Results}

We invited a total of 1002 healthcare workers to participate in the study, from which 645 people completed the survey (response rate: 64.4\%). Thirty respondents declared that they had not taken care of COVID-19 patients, leaving a total of 615 completed questionnaires for analysis.

Table 1 illustrates the baseline characteristics as well as the mean MBI scores in each subscale.

Our findings showed that 55 (8.9\%), 252 (41.0\%), and 308 $(50.1 \%)$ people experienced low, moderate, and high levels in the emotional exhaustion axis, respectively. In the depersonalization axis, the values for low, moderate, and high levels of burnout were $5(0.8 \%), 529(86.0 \%)$, and $81(13.2 \%)$, respectively. In addition, only one $(0.8 \%)$ participant scored low in personal accomplishment axis, while $88(14.3 \%)$ and $526(85.5 \%)$ people were shown to experience moderate or high levels, respectively.

Table 2 illustrates how the level of burnout in each subscale varies between different groups of participants in terms of sociodemographic variables and job category. Among the studied characteristics, gender was the only variable that was associated with high levels of all three domains of burnout. High emotional exhaustion was significantly more prevalent in females and those without children, as well as people from different job categories (most common in residents and then nurses). High levels of depersonalization were significantly more common in males and younger ( $\leq 36$ years) participants.

We noted that of all 615 participants in the study, who had completed the MBI questionnaire, 326 persons (53.0\%) experienced high levels of burnout. Table 3 shows the distribution of high burnout in different groups of participants
Table 1 Baseline characteristics of participants $(n=615)$

\begin{tabular}{|c|c|}
\hline Variable & Value \\
\hline Age in years, Mean $\pm S D$, (range) & $34.4 \pm 7.8,(22-67)$ \\
\hline \multicolumn{2}{|l|}{ Gender, $n(\%)$} \\
\hline Female & $403(65.5)$ \\
\hline Male & $208(33.8)$ \\
\hline Prefer not to say & $4(0.7)$ \\
\hline \multicolumn{2}{|l|}{ Marital status, $n(\%)$} \\
\hline Married & $363(59.0)$ \\
\hline Single & $242(39.4)$ \\
\hline Prefer not to say & $10(1.6)$ \\
\hline \multicolumn{2}{|l|}{ Home living children, $n(\%)$} \\
\hline Yes & $229(37.2)$ \\
\hline No & $386(62.8)$ \\
\hline \multicolumn{2}{|l|}{ Job category, $n(\%)$} \\
\hline Specialist & $68(11.1)$ \\
\hline Resident & $166(27.0)$ \\
\hline Intern & $19(3.1)$ \\
\hline Nurse & $300(48.8)$ \\
\hline Other & $62(10.1)$ \\
\hline Years in practice, Mean \pm SD & $8.8 \pm 6.7$ \\
\hline days working over past month, Mean \pm SD & $18.1 \pm 9.1$ \\
\hline hours working per shift, Mean \pm SD & $13.3 \pm 6.5$ \\
\hline \multicolumn{2}{|l|}{ Maslach Burnout Inventory Score, Mean \pm SD } \\
\hline Total score & $64.2 \pm 7.7$ \\
\hline Emotional Exhaustion Subscale Score & $26.6 \pm 7.4$ \\
\hline Depersonalization Subscale Score & $10.2 \pm 2.2$ \\
\hline Personal Accomplishment Subscale Score & $27.3 \pm 3.9$ \\
\hline
\end{tabular}

$n$ number, $S D$ standard deviation, COVID-19 corona virus disease 2019

based on their sociodemographic characteristics and workrelated factors.

The results of multiple logistic regression analysis of different variables to detect their impact on the development of high burnout levels have been presented in Table 4 . Age, gender, job category, and work site were significantly associated with burnout status; while marital status, having children, number of years in practice, and the average daily workload were not associated with this outcome.

\section{Discussion}

The results of this cross-sectional survey demonstrated high levels of burnout in healthcare workers looking after COVID-19 patients. We also found that younger age and female gender were predisposing factors for burnout and that the level of burnout varied significantly by site of practice and job category. 
Table 2 Participant's level of burnout in each dimension by sociodemographic characteristics and job category, number (\%)

\begin{tabular}{|c|c|c|c|c|c|c|c|c|c|c|c|c|}
\hline & \multicolumn{4}{|c|}{ Emotional Exhaustion } & \multicolumn{4}{|c|}{ Depersonalization } & \multicolumn{4}{|c|}{ Personal Accomplishment } \\
\hline & Low & Moderate & High & $P$ & Low & Moderate & High & $P$ & Low & Moderate & High & $P$ \\
\hline \multicolumn{13}{|l|}{ Age } \\
\hline$\leq 36$ year & $36(8.9)$ & $154(38)$ & $215(53.1)$ & 0.105 & $3(0.7)$ & $338(83.5)$ & $64(15.8)$ & 0.011 & $1(0.2)$ & 59 (14.6) & $345(85.2)$ & 0.723 \\
\hline$>36$ year & $19(9.0)$ & $98(46.7)$ & $93(44.3)$ & & $2(1.0)$ & $191(91.0)$ & $17(8.1)$ & & $0(0)$ & $29(13.8)$ & $181(86.2)$ & \\
\hline \multicolumn{13}{|l|}{ Gender } \\
\hline Female & $30(7.4)$ & $148(36.7)$ & $225(55.8)$ & $<0.001$ & $3(0.7)$ & $359(89.1)$ & $41(10.2)$ & 0.003 & $0(0.0)$ & $45(11.2)$ & $358(88.8)$ & 0.003 \\
\hline Male & $25(12.0)$ & $102(49.0)$ & $81(38.9)$ & & $2(1.0)$ & $166(79.8)$ & $40(19.2)$ & & $1(0.5)$ & $42(20.2)$ & $165(79.3)$ & \\
\hline \multicolumn{13}{|c|}{ Marital status } \\
\hline Married & $40(11.0)$ & $142(39.1)$ & $181(49.9)$ & 0.436 & $4(1.1)$ & $318(87.6)$ & $41(11.3)$ & 0.077 & $1(0.3)$ & $57(15.7)$ & $305(84.0)$ & 0.327 \\
\hline Single & $15(6.2)$ & $105(43.4)$ & $122(50.4)$ & & $1(0.4)$ & $202(83.5)$ & $39(16.1)$ & & $0(0.0)$ & $30(12.4)$ & $212(87.6)$ & \\
\hline Other & $0(0.0)$ & $5(50.0)$ & $5(50.0)$ & & $0(0.0)$ & $9(90.0)$ & $1(10.0)$ & & $0(0.0)$ & $1(10.0)$ & $9(90.0)$ & \\
\hline \multicolumn{13}{|c|}{ Having children } \\
\hline Yes & $24(10.5)$ & $104(45.4)$ & 101(44.1) & 0.027 & $2(0.9)$ & $206(90.0)$ & $21(9.2)$ & 0.033 & $1(0.4)$ & $43(18.8)$ & $185(80.8)$ & 0.010 \\
\hline No & $31(8.0)$ & $148(38.3)$ & 207 (53.6) & & $3(0.8)$ & $323(83.7)$ & $60(15.5)$ & & $0(0)$ & 45 (11.7) & $341(88.3)$ & \\
\hline \multicolumn{13}{|l|}{ Job category } \\
\hline Specialist & $7(10.3)$ & $31(45.6)$ & $30(44.1)$ & 0.008 & $0(0.0)$ & $65(95.6)$ & $3(4.4)$ & 0.657 & $0(0.0)$ & $8(11.8)$ & $60(88.2)$ & $<0.001$ \\
\hline Resident & $7(4.2)$ & $59(35.5)$ & $100(60.2)$ & & $2(1.2)$ & 134 (80.7) & $30(18.1)$ & & $0(0.0)$ & $7(4.2)$ & $159(95.8)$ & \\
\hline Intern & $1(5.3)$ & $14(73.7)$ & $4(21.1)$ & & $0(0.0)$ & $18(94.7)$ & $1(5.3)$ & & $0(0.0)$ & $3(16.8)$ & $16(84.2)$ & \\
\hline Nurse & $26(8.7)$ & $115(38.3)$ & $159(53.0)$ & & $3(1.0)$ & 257 (85.7) & $40(13.3)$ & & $1(0.3)$ & $47(15.7)$ & $252(84.0)$ & \\
\hline Other & $14(22.6)$ & $33(53.2)$ & $15(24.2)$ & & $0(0.0)$ & $55(88.7)$ & $7(11.3)$ & & $0(0.0)$ & $23(37.1)$ & $39(62.9)$ & \\
\hline
\end{tabular}

$p p$ value

Other studies have also investigated the psychological impact of COVID-19 and other infectious disease outbreaks on hospital staff. A recent rapid review of the existing literature retrieved 59 papers that described the emotional reactions of HCPs during an outbreak of viral infectious disease (Kisely et al. 2020). The investigators concluded that staff in contact with these patients had greater levels of acute or posttraumatic stress (odds ratio $1.71,95 \%$ CI 1.28-2.29) and psychological distress (1.74, 1.50-2.03) as compared with lower risk controls (Kisely et al. 2020). Most of the studies used instruments other than MBI, and only eight were on COVID-19. Poon et al. using State-Trait Anxiety Inventory conducted a survey to identify anxiety levels among 1926 front-line healthcare workers in Hong Kong during SARS outbreak. They also used the emotional exhaustion dimension of the MBI. Mean anxiety levels $(51.1$ versus $47.1 ; p<0.001)$ and the number of burnout symptoms ( 7.3 versus $5.1 ; p<0.001$ ) among front-line health care workers were higher than those among controls; anxiety scores correlated with burnout scores (2004). An online survey was performed to investigate the role of perceived SARS threat and organizational support in predicting emotional exhaustion and stated anger among 333 Canadian nurses (315 women, 18 men) (Fiksenbaum et al. 2006). In this study, mean emotional exhaustion score was $4( \pm 1.85)$. In a cross-sectional survey conducted in China, using General Health
Questionnaire, Dai et al. evaluated mental health status of a convenient sample of 4357 healthcare workers (2020). They found that 1704 workers (39.1\%) had psychological distress (score $\geq 3$ ). In another survey, Lai and colleagues assessed the magnitude of mental health outcomes of 1257 healthcare workers treating patients exposed to COVID19 in 34 hospitals in China. They found that 634 people (50.4\%) reported symptoms of depression, 560 (44.6\%) anxiety, 427 (34.0\%) insomnia, and 899 (71.5\%) distress (2019). Moreover, Liu et al. using the Zung self-rating anxiety Scale, estimated the prevalence of anxiety among medical staff to be $12.5 \%$ (2020). Xing et al. in a crosssectional survey using Symptom Checklist-90 (SCL-90) investigated the mental health status of 548 medical personnel dealing with COVID-19 at 12 hospitals in eight provinces and cities of China (2020). According to the findings of their study, overall average score of SCL90 among medical personnel were significantly higher than that of the norm group. Zhu et al. evaluated stress, depression, and anxiety among 5,062 health workers using Impact of Event Scale-Revised, Patient Health Questionnaire-9, and Generalized Anxiety Disorder 7-item. In this study, 29.8 percent of participants reported stress, 13.5\% depression, and $24.1 \%$ anxiety (2020). In a study by Maunder et al. on 587 workers at Toronto Hospital, 30.4\% had high emotional exhaustion (score $\geq 27$ ) (2006). To the best of our knowledge, no prior study used MBI to assess the 
Table 3 Frequency of high burnout in different groups of participants $(n=615)$

\begin{tabular}{|c|c|c|c|}
\hline \multirow[t]{2}{*}{ Variable } & \multicolumn{2}{|c|}{ High burn out level, $n(\%)$} & \multirow[t]{2}{*}{$P$ value } \\
\hline & No & Yes & \\
\hline Age & & & 0.041 \\
\hline$\leq 36$ years & $177(43.7)$ & $228(56.3)$ & \\
\hline$>36$ years & $110(52.4)$ & $100(47.6)$ & \\
\hline Gender & & & 0.002 \\
\hline Female & $169(41.9)$ & $234(58.1)$ & \\
\hline Male & $116(55.8)$ & $92(44.2)$ & \\
\hline Other & $2(50)$ & $2(50)$ & \\
\hline Marital status & & & 0.877 \\
\hline Married & $172(47.4)$ & $191(52.6)$ & \\
\hline Single & $110(45.5)$ & $132(54.5)$ & \\
\hline Other & $5(50.0)$ & $5(50.0)$ & \\
\hline Home living children & & & 0.030 \\
\hline Yes & $120(52.4)$ & $109(47.6)$ & \\
\hline No & $167(43.3)$ & $219(56.7)$ & \\
\hline Job category & & & $<0.001$ \\
\hline Intern & $14(73.7)$ & $5(26.3)$ & \\
\hline Resident & $58(34.9)$ & $108(65.1)$ & \\
\hline Specialist & $37(54.4)$ & $31(45.6)$ & \\
\hline Nurse & $134(44.7)$ & $166(55.3)$ & \\
\hline Other & $44(71.0)$ & $18(29.0)$ & \\
\hline Hospital & & & 0.002 \\
\hline Shohada & $105(57.1)$ & $79(42.9)$ & \\
\hline Imam Hussein & $107(41.8)$ & $149(58.2)$ & \\
\hline Masih Daneshvari & $42(50)$ & $42(50)$ & \\
\hline Other & $33(36.3)$ & $5863.7)$ & \\
\hline Years in practice & & & 0.042 \\
\hline$\leq 5$ years & $112(41.9)$ & $155(58.1)$ & \\
\hline$>5$ years & $175(50.3)$ & $173(49.7)$ & \\
\hline Average daily workload ${ }^{\mathrm{a}}$ & & & 0.561 \\
\hline$\leq 8 \mathrm{~h}$ & $202(47.4)$ & $224(52.6)$ & \\
\hline$>8 \mathrm{~h}$ & 83 (44.9) & $102(55.1)$ & \\
\hline
\end{tabular}

${ }^{\mathrm{a}}$ There were four missing values

psychological sequel of COVID-19; therefore, a comparison of the results of this study with that of previous studies is not feasible.

Burnout is a very well-known consequence of healthcare for the staff and is strongly linked to significant outcomes such as patient safety (Dewa et al. 2017; Hall et al. 2016); Moreover, MBI is a validated instrument to assess the level of burnout. Therefore, we believe that MBI is a practical and credible method for assessment of the psychological impact of COVID-19 pandemic on staff.

Our study lacked a control group but a comparison of our findings with other studies on burnout in our country before the COVID-19 pandemic shows a much higher level of burnout. A systematic review of the studies which examined the
Table 4 Bivariate associations between high level of burnout and sociodemographic and work-related factors $(n=611)$

\begin{tabular}{lllll}
\hline Variable & OR & \multicolumn{2}{l}{$95 \%$ CI for OR } & $P$ value \\
\cline { 3 - 4 } & & Lower limit & Upper limit & \\
\hline Age $^{\mathrm{a}}$ & 0.97 & 0.95 & 0.99 & 0.010 \\
Gender & & & & 0.015 \\
Female & 1 & & 0.92 & \\
Male & 0.65 & 0.45 & & $<0.001$ \\
Job category & & & & \\
Intern & 1 & & 20.41 & 0.001 \\
Resident & 6.64 & 2.16 & 13.48 & 0.026 \\
Specialist & 4.13 & 1.18 & 5.90 & 0.006 \\
Nurse & 4.56 & 1.54 & & 0.011 \\
Other & 1.77 & 0.53 & & \\
Hospital & & & 2.78 & 0.002 \\
Shohada & 1 & & 2.23 & 0.364 \\
Imam hussein & 1.86 & 1.25 & 3.53 & 0.026 \\
Masih daneshvari & 1.29 & 0.74 & & \\
Other & 1.96 & 1.08 & &
\end{tabular}

$n$ number, $y r$ year, $S D$ standard deviation, $C I$ confidence interval, $O R$ odds ratio

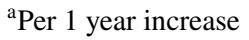

prevalence of burnout among nurses in Iran, published in 2018 , found that the overall prevalence of burnout among Iranian nurses was 36\% (95\% CI 20-53\%) (Rezaei et al. 2018). In our study, more than $55 \%$ of the nurses experienced high burnout during the COVID-19 pandemic. In a cross-sectional study conducted on 208 primary HCPs in Iran, the average score of the participants in emotional exhaustion dimension was 17.19 , compared to around 27 in our study (Khosravi et al. 2017). A large study to assess the level of job burnout among 1,807 HCPs in Iran found that mean scores $( \pm \mathrm{SD})$ in emotional exhaustion, depersonalization, and personal accomplishment subscales were 8.9 $( \pm 9.0), 23( \pm 2.9)$, and $34( \pm 8.6)$, respectively (Bazmi et al. 2019); while in our study, these values were much higher: $26.6( \pm 7.4), 10.2( \pm 2.2)$, and $27.3( \pm 3.9)$, respectively.

Several outbreaks of infectious diseases have occurred over the past two decades and they represent a serious threat to both health services and staff. HCPs taking care of a large number of potentially infectious victims are under great physical and psychological pressure. Therefore, it is not surprising to expect a high rate of mental health problems among the staff. Chen et al. interviewed 13 medical staff at a hospital in China during the COVID-19 outbreak and noted that "getting infected was not an immediate worry to staff" but that "they were afraid of bringing the virus to their home". They also stated that issues such as ambiguity regarding "how to deal with patients when they were unwilling to be quarantined at the hospital or did not cooperate 
with medical measures because of panic or a lack of knowledge about the disease" and "shortage of protective equipment" were also contributing to poor mental health of medical staff (2020). A study by Sahashi et al. on 4,386 HCPs in Japan also found that consequence of becoming infected, restricted social contact, and a shortage in personal protective equipment were the most frequent concerns (2019). While our study was not meant to discover the reasons for this phenomenon, several issues can be speculated to have resulted in this state of high burnout. Heavy workload, fear of contracting the disease or transmitting it to the family, as well as lack of staff support systems are often cited complaints. These are, however, anecdotal report remembered by the investigators and are not part of the formal data obtained through this study. Whether these are linked to the development of high burnout or not and the contribution of each potential factor can be the subject of future studies. This will help administrators adapt the best approach to maintain staff mental health.

Our study found age and gender to be important predisposing factors for high burnout. Our findings are in accordance with several studies showing that staff who are women (Chong et al. 2004; Lai et al. 2019; Zhu et al. 2020; Tang et al. 2016; Bukhari et al. 2016; Huang et al. 2020) or younger (Austria-Corrales et al. 2011; Nickell et al. 2004; Tam et al. 2004; Wu et al. 2009; Sim et al. 2004) are more vulnerable to psychological distress. Only in two studies, older age was a risk factor for psychological symptoms (Xing et al. 2020; Wu et al. 2009).

While some studies have found out that having children (Koh et al. 2005; Maunder et al. 2004) and having an increased contact with affected patients (Poon et al. 2004; Fiksenbaum et al. 2006; Dai et al. 2020; Lai et al. 2019; Maunder et al. 2004, 2006; Tang et al. 2016; Bukhari et al. 2016; Huang et al. 2020; Nickell et al. 2004; Tam et al. 2004; Wu et al. 2009; Koh et al. 2005; Lee et al. 2018; Kim and Choi 2016; Oh et al. 2017; Matsuishi et al. 2012; Styra et al. 2008; Liu et al. 2012; Goulia et al. 2010) are predisposing factors, our study failed to find such a relationship. Moreover, several studies have shown that being less experienced (Chong et al. 2004; Tang et al. 2016; Oh et al. 2017; Lancee et al. 2008) puts the staff at higher risk. While we found a significant difference between the experience of those with and without high burnout, this variable did not remain in the final regression model, pointing to potential co-linearity between age and experience.

Within the job categories, residents were found in this study to be at higher risk of developing high burnout. Nurses were the second at-risk group. In previous studies, nurses were generally at higher risk than doctors (Poon et al. 2004; Lai et al. 2019; Nickell et al. 2004; Tam et al. 2004; Koh et al. 2005; Maunder et al. 2004; Goulia et al. 2010; Wong et al. 2005). Lai et al., for example, reported more severe degrees of all measurements of mental health symptoms in nurses exposed to COVID-19 (2019). However, two studies reported the opposite (Chan and Huak 2003; Lung et al. 2009). A survey of 99 residents during a H1N1 influenza virus outbreak in Mexico City conducted documented high levels of burnout among this population (Austria-Corrales et al. 2011). The reasons why residents were so vulnerable to burnout needs further study, but issues such as heavy workload, changes in duty rosters to accommodate the new needs, and cancelation of vacations, as well as having less access to personal protective equipment may have caused this unfavorable state.

The level of burnout in our study was also affected by the location of work. In a study by Maunder on 769 healthcare workers during SARS outbreak, the investigators found a significantly higher levels of burnout in the staff of one of the two studied hospitals (median score 19, interquartile [IQR] range 10-29, in one hospital versus median score 16, IQR 9- 23, in the other hospital) (Maunder et al. 2006). Dai et al. found that working in primary hospitals was a poor prognostic factor (2020). In our study, working in the hospitals which were not designated as COVID-19 centers was accompanied by higher levels of burnout. We cannot provide evidence-based reasons for this finding. The investigators tried to speculate through their experience some justifications, but these are not rooted in our findings. Several reasons might account for this difference: working conditions affects perceived threat; designated hospitals are better prepared and equipped for healthcare delivery to COVID-19 patients; working in non-designated hospitals is not rewarded by recognition and incentives often found in COVID-19 designated hospitals. These guesses, again, need to be tested in future studies.

Our study has several strengths. Burnout is a well-recognized psychological consequence of working in the healthcare section and its impact on staff physical and emotional health, patient safety, and quality of care is documented. The instrument used in this study is well validated across geographical areas. We used a relatively large sample with an acceptable response rate. The study population in our study come from different hospitals ranging from small district hospitals to tertiary care teaching hospitals. They also represent different job categories from ancillary staff to board-certified attending physicians and clinical teachers. This reassures us that our sample represent the total healthcare providers in the country.

This study also faces some limitations. We used a convenience sampling strategy and this may have resulted in selection bias. Unfortunately, we did not have access to sociodemographic and work-related data of the non-responders to check for any potential discrepancy between responders and non-responders. Although we tried to consider several personal (e.g., marital status and having dependent children) 
and work-related parameters (e.g., workload, job category), our study might have failed to deal with all contributing factors. We specifically referred to COVID-19 in our questions; however, since we did not have a control group, a comparison with other clinicians or the general population has not been performed and we cannot claim that this level of burnout is solely attributable to COVID-19 pandemic. Furthermore, the observational nature and the design of our study makes it impossible to make any inferences regarding causality. Since job descriptions and responsibilities of different healthcare providers may vary slightly in other healthcare systems, caution should be applied when generalizing the findings of this study to other settings.

In summary, our study highlighted the high prevalence of burnout among HCPs caring for patients during the new pandemic. Several personal and work-related factors contribute to the level of burnout that the staff experience. These include younger age, female gender, working as a resident or nurse, and working in non-COVID-designated hospitals.

Acknowledgements We would like to thank the healthcare providers who took their time out of their busy days to complete the questionnaire. The first draft of this paper has been published on MedRxiv.

Author contributions All authors have made substantive contributions to the study, and all authors endorse the data and conclusions.

Funding No financial support or funding was provided for this study.

\section{Declarations}

Conflict of interest The authors have no competing interests to declare.

\section{References}

Austria-Corrales F, Cruz-Valdés B, Herrera-Kiengelher L, VázquezGarcía JC, Salas-Hernández J (2011) Burnout syndrome among medical residents during the influenza A H1N1 sanitary contigency in Mexico. Gac Med Mex 147:97-103

Bazmi E, Alipour A, Yasamy MT et al (2019) Job burnout and related factors among health sector employees. Iran J Psychiatry 14(4):309-316

Bukhari EE, Temsah MH, Aleyadhy AA et al (2016) Middle east respiratory syndrome coronavirus (MERS-CoV) outbreak perceptions of risk and stress evaluation in nurses. J Infect Dev Ctries 10:845-850. https://doi.org/10.3855/jidc.6925

Chan AOM, Huak CY (2004) Psychological impact of the 2003 severe acute respiratory syndrome outbreak on health care workers in a medium size regional general hospital in Singapore. Occup Med 54:190-196. https://doi.org/10.1093/occmed/kqh027

Chen Q, Liang M, Li Y et al (2020) Mental health care for medical staff in China during the COVID-19 outbreak. Lancet Psychiatry 7(4):e15-e16. https://doi.org/10.1016/S2215-0366(20)30078-X

Chong MY, Wang W-C, Hsieh WC et al (2004) Psychological impact of severe acute respiratory syndrome on health workers in a tertiary hospital. Br J Psychiatry 185:127-133
Dai Y, Hu G, Xiong H 2020 Psychological impact of the coronavirus disease 2019 (COVID-19) outbreak on healthcare workers in China. medRxiv 2020.03.03.20030874 [Preprint]

Dewa CS, Jacobs P, Thanh NX, Loong D (2014) An estimate of the cost of burnout on early retirement and reduction in clinical hours of practicing physicians in Canada. BMC Health Serv Res 14:254

Dewa CS, Loong D, Bonato S, Trojanowski L (2017) The relationship between physician burnout and quality of healthcare in terms of safety and acceptability: a systematic review. BMJ Open 7(6):e015141. https://doi.org/10.1136/bmjopen-2016-015141

Draper H, Wilson S, Ives J et al (2008) Healthcare workers' attitudes towards working during pandemic influenza: a multi method study. BMC Public Health 8:192. https://doi.org/10.1186/ 1471-2458-8-192

Fiksenbaum L, Marjanovic Z, Greenglass E, Coffey S (2006) Emotional exhaustion and state anger in nurses who worked during the SARS outbreak: the role of perceived threat and organizational support. Can J Commun Ment Health 25(2):89-103

Goulia P, Mantas C, Dimitroula D, Mantis D, Hyphantis T (2010) General hospital staff worries, perceived sufficiency of information and associated psychological distress during the A/H1N1 influenza pandemic. BMC Infect Dis 10:322. https://doi.org/10. 1186/1471-2334-10-322

Guo J, Liao L, Wang B et al (2020) Psychological effects of COVID-19 on hospital staff: a national cross-sectional survey of China mainland. Lancet Psychiatry. https://doi.org/10.4103/VIT-2

Hall LH, Johnson J, Watt I, Tsipa A, O'Connor DB (2016) Healthcare staff wellbeing, burnout, and patient safety: a systematic review. PLoS ONE 11(7):e0159015. https://doi.org/10.1371/journal.pone. 0159015

Huang L, Xu F, Liu H (2020) Emotional responses and coping strategies of nurses and nursing college students during COVID-19 outbreak. medRxiv 2020.03.05.20031898 [Preprint]

Ing EB, Xu Q, Salimi A, Torun N (2020) Physician deaths from corona virus (COVID-19) disease. Occup Med 70(5):370-374

In Memoriam: Healthcare Workers Who Have Died of COVID-19 Medscape - Apr 01, 2020. Available through: https://www.medsc ape.com/viewarticle/927976\#vp_1. Accessed 16 Apr 2020

Jin Y-H, Cai L, Cheng Z-S, Cheng H et al (2020) A rapid advice guideline for the diagnosis and treatment of 2019 novel coronavirus (2019-nCoV) infected pneumonia (standard version). Mil Med Res 7(1):4

Khosravi A, Ranjbar M, Erfan A, Sadeghi Z, khojasteh L, Amiri M. "Burnout in Primary Health Care Providers in Mazandaran Province." International Journal of Health Studies [Online], 3.4 (2017): n. pag. Web. 31 May. 2020

Kim JS, Choi JS (2016) Factors influencing emergency nurses' burnout during an outbreak of middle east respiratory syndrome coronavirus in Korea. Asian Nurs Res 10:295-299. https://doi.org/10. 1016/j.anr.2016.10.002 (Korean Soc Nurs Sci)

Kisely S, Warren N, McMahon L, Dalais C, Henry I, Siskind D (2020) Occurrence, prevention, and management of the psychological effects of emerging virus outbreaks on healthcare workers: rapid review and meta-analysis. BMJ 369:m1642. https://doi.org/10. 1136/bmj.m1642 (Published online 5 May 2020)

Koh D, Lim MK, Chia SE et al (2005) Risk perception and impact of severe acute respiratory syndrome (SARS) on work and personal lives of healthcare workers in Singapore: what can we learn? Med Care 43:676-682. https://doi.org/10.1097/01.mlr.0000167181. 36730.cc

Lai J, Ma S, Wang Y et al (2020) Factors associated with mental health outcomes among health care workers exposed to coronavirus disease 2019. JAMA Netw Open. 3(3):e203976. https://doi.org/10. 1001/jamanetworkopen.2020.3976

Lancee WJ, Maunder RG, Goldbloom DS, Coauthors for the Impact of SARS Study (2008) Prevalence of psychiatric disorders among 
Toronto hospital workers one to two years after the SARS outbreak. Psychiatr Serv. 59(1):91-95. https://doi.org/10.1176/ps. 2008.59.1.91

Lee SM, Kang WS, Cho A-R, Kim T, Park JK (2018) Psychological impact of the 2015 MERS outbreak on hospital workers and quarantined hemodialysis patients. Compr Psychiatry 87:123-127. https://doi.org/10.1016/j.comppsych.2018.10.003

Liu X, Kakade M, Fuller CJ et al (2012) Depression after exposure to stressful events: lessons learned from the severe acute respiratory syndrome epidemic. Compr Psychiatry 53:15-23. https://doi.org/ 10.1016/j.comppsych.2011.02.003

Liu CY, Yang YZ, Zhang XM et al (2020) The prevalence and influencing factors in anxiety in medical workers fighting COVID-19 in China: a cross-sectional survey. Epidemiol Infect. 148:e98. https:// doi.org/10.1017/S0950268820001107

Lung F-W, Lu Y-C, Chang Y-Y, Shu BC (2009) Mental symptoms in different health professionals during the SARS attack: a follow-up study. Psychiatr Q 80:107-116. https://doi.org/10.1007/ s11126-009-9095-5

Maslach C, Jackson SE (1981) The measurement of experienced burnout. J Occup Behav 2:99-113

Maslach C, Jackson S, Leiter M (1996) Maslach burnout inventory manual. CPP. Inc., and Davies-Black, Mountain View, CA

Matsuishi K, Kawazoe A, Imai H et al (2012) Psychological impact of the pandemic (H1N1) 2009 on general hospital workers in Kobe. Psychiatry Clin Neurosci 66:353-360. https://doi.org/10.1111/j. 1440-1819.2012.02336.x

Maunder RG, Lancee WJ, Rourke S et al (2004) Factors associated with the psychological impact of severe acute respiratory syndrome on nurses and other hospital workers in Toronto. Psychosom Med 66:938-942. https://doi.org/10.1097/01.psy.00001 45673.84698.18

Maunder RG, Lancee WJ, Balderson KE et al (2006) Long-term psychological and occupational effects of providing hospital healthcare during SARS outbreak. Emerg Infect Dis 12(12):1924-1932. https://doi.org/10.3201/eid1212.060584

Moalemi S, Kavosi Z, Beygi N, Deghan A, Karimi A, Parvizi MM (2018) Evaluation of the Persian version of Maslach burnout inventory-human services survey among Iranian nurses: validity and reliability. GMJ. 7:e995

Nickell LA, Crighton EJ, Tracy CS et al (2004) Psychosocial effects of SARS on hospital staff: survey of a large tertiary care institution. CMAJ 170:793-798. https://doi.org/10.1503/cmaj.1031077

Oh N, Hong N, Ryu DH, Bae SG, Kam S, Kim KY (2017) Exploring nursing intention, stress, and professionalism in response to infectious disease emergencies: the experience of local public hospital nurses during the 2015 MERS outbreak in South Korea. Asian Nurs Res 11:230-236. https://doi.org/10.1016/j.anr.2017.08.005 (Korean Soc Nurs Sci)

Poon E, Liu KS, Cheong DL, Lee CK, Yam LYC, Tang WN (2004) Impact of severe acute respiratory syndrome on anxiety levels of frontline health care workers. Hong Kong Med J 10:325-330

Rezaei S, Karami Matin B, Hajizadeh M, Soroush A, Nouri B (2018) Prevalence of burnout among nurses in Iran: a systematic review and meta-analysis. Int Nurs Rev 65(3):361-369. https://doi.org/ 10.1111/inr.12426

Sahashi Y, Endo H, Sugimoto T et al (2020) Worries and concerns among healthcare workers during the coronavirus 2019 pandemic: a web-based cross-sectional survey. medRxiv. https://doi.org/10. $1101 / 2020.06 .09 .20126045$
SARS Commission (2006) Spring of fear, volumes 1, 2 and 3. Toronto (ON). Canada

Shanafelt TD, Dyrbye LN, West CP, Sinsky CA (2016) Potential impact of burnout on the US physician workforce. Mayo Clin Proc 91:1667-1668

Sim K, Chua HC (2004) The psychological impact of SARS: a matter of heart and mind. CMAJ 170(5):811-812

Sim K, Chong PN, Chan YH, Soon WS (2004) Severe acute respiratory syndrome-related psychiatric and posttraumatic morbidities and coping responses in medical staff within a primary health care setting in Singapore. J Clin Psychiatry 65:1120-1127. https://doi. org/10.4088/JCP.v65n0815

Styra R, Hawryluck L, Robinson S, Kasapinovic S, Fones C, Gold WL (2008) Impact on health care workers employed in high-risk areas during the Toronto SARS outbreak. J Psychosom Res 64:177-183. https://doi.org/10.1016/j.jpsychores.2007.07.015

Tam CWC, Pang EPF, Lam LCW, Chiu HF (2004) Severe acute respiratory syndrome (SARS) in Hong Kong in 2003: stress and psychological impact among frontline healthcare workers. Psychol Med 34:1197-1204. https://doi.org/10.1017/S0033291704002247

Tang L, Pan L, Yuan L, Zha L (2016) Prevalence and related factors of posttraumatic stress disorder among medical staff members exposed to H7N9 patients. Int J Nurs Sci 4:63-67. https://doi.org/ 10.1016/j.ijnss.2016.12.002

Walkey FH, Green DE (1992) An exhaustive examination of the replicable factor structure of the Maslach burnout inventory. Educ Psychol Measur 52:309-323

Wong TW, Yau JK, Chan CL et al (2005) The psychological impact of severe acute respiratory syndrome outbreak on healthcare workers in emergency departments and how they cope. Eur J Emerg Med 12:13-18. https://doi.org/10.1097/00063110-200502000-00005

World Health Organization (2003) Summary table of SARS cases by country, 1 November 2002-2007. Geneva (CH). Aug 2003

World Health Organization (2019) https://www.who.int/emergencies/ diseases/novel-coronavirus-2019. Accessed 21 Nov 2020

World Health Organization (2020a) Coronavirus disease (COVID2019) situation reports. www.who.int/emergencies/diseases/novelcoronavirus-2019/situation-reports-on-2-May-2020. Accessed 21 November 2020

World Health Organization (2020b) Covid-19 weekly epidemiological update. www.who.int/publications/m/item/weekly-epidemiolo gical-update---17-november-2020. Accessed 21 Nov 2020

Wu P, Fang Y, Guan Z et al (2009) The psychological impact of the SARS epidemic on hospital employees in China: exposure, risk perception, and altruistic acceptance of risk. Can J Psychiatry 54:302-311. https://doi.org/10.1177/070674370905400504

Xing J, Sun N, Xu J, Geng S, Li Y (2020) Study of the mental health status of medical personnel dealing with new coronavirus pneumonia. PLoS ONE 15(5):e0233145. https://doi.org/10.1371/journ al.pone. 0233145

Zhu Z, Xu S, Wang H. COVID-19 in Wuhan: immediate psychological impact on 5062 health workers. medRxiv 2020 2020.02.20.20025338 [Preprint]

Publisher's Note Springer Nature remains neutral with regard to jurisdictional claims in published maps and institutional affiliations. 